\title{
Case Study on the Design and Teaching of MOOC: English Grammar
}

\author{
Wei Gong \\ Chengdu College of University of Electronic Science and Technology of China \\ Chengdu, China
}

\author{
Shen $\mathrm{Hu}$ \\ Chengdu College of University of Electronic Science and \\ Technology of China \\ Chengdu, China
}

\author{
Xuehua Ren \\ Chengdu College of University of Electronic Science and \\ Technology of China \\ Chengdu, China
}

\begin{abstract}
English grammar is a MOOC via Chaoxing MOOC platform for first year undergraduate students in our college. This essay reports the development and delivery of this course, aiming at exploring the contribution that a MOOC curriculum platform can bring to the establishment of an interactive and networked College English grammar learning resource library. A mixed methods research was adopted to investigate the teachers' and learners' perceptions and evaluations of the curriculum, in the hope of providing some implications to promote teaching and learning online.
\end{abstract}

\section{Keywords—MOOC; English grammar; Chaoxing}

\section{INTRODUCTION}

The teaching of college English grammar in China has been in a highly controversial and extremely embarrassing situation due to the lack of teaching materials and class hours. On the one hand, in traditional classrooms, where overt grammatical knowledge is emphasized and students may have spent many hours practicing the rules for correct sentence formation without knowing how to use grammar as a resource in communication, the students show little interest and the teaching effect is poor. On the other hand, in communicative classrooms and task-based learning, teachers spend so much time getting through the content while other aspects, such as grammar, get pushed aside. As Flowerdew and Peacock (2014) summed up, "More grammar, but there is no time!" Moreover, students placed in the same course are commonly at different proficiency levels so that the pace of the language class is slow down as it's hard to work with their classmates. Therefore, the problem of how and when to focus on grammar has its origins in the very difficult balance that is inherent in college English class between skills, content and language, so the solutions must begin here also. For this reason, we would like to suggest pedagogical reformation for integrating grammar into the communicative class systematically. That is to say, much of what is often taught in traditional grammar courses that focus on sentencebased practice can be assigned for self-study (Richards\& Reppen, 2014), using the resources that modern information technology provides, and technology plus internet can also help to reconstruct an interactive and collaborative classroom in a real language environment. The emergence of MOOC just provides us such a good platform.

MOOC (Massive Open Online Course), a large-scale online course, due to its characteristics of "giant", "diversity" and "humanization" (M. Li, 2013), has drawn more and more attention so that colleges and universities alliances began to use the curriculum platform to build online courses and all kinds of network media have also developed a variety of MOOC curriculum platform in China since the year 2013. However compared with other subjects, the number of language courses is rather small. MOOC, China University MOOC, Superstar MOCC and Wisdom Tree (Q. Bi, 2015) are the key words of "English Grammar". Among the four major platforms, there are no relevant courses. Only the MOOC "The English Grammar and Writing", lectured by an associate professor of Foreign Language and Literature at Jinan University, is provided online. This course combines English grammar with writing. However, its focus is to apply syntactic knowledge to discourse writing. Almost no issues of compound sentences and complex sentences, which puzzled college students a lot, were addressed.

Therefore, we conducted explorations of using MOOC curriculum platform to build an online classroom of college English grammar. Based on our college English grammar online course (hereinafter referred to as "grammar online") case study, this paper studies how the MOOC course helps students to acquire grammatical knowledge and translate it into grammar skills, so as to provide some practice for the reform of college English grammar teaching and theoretical reference.

\section{CURRICULUM DESIGN AND DEVELOPMENT}

Grammar online course is built on Chaoxing Fanya MOOC learning platform, whose functions cover the entire teaching process of course construction, course learning, learning community, learning analysis and course management. Teachers can use the platform for long-term 
cycle of curriculum development, including curriculum development, curriculum basic information maintenance, interactive event organization, learning and curriculum evaluation organization and management, network support pure teaching, mixed-mode teaching, teaching and other network-assisted teaching mode. Students can log in using the platform site courses, curriculum study, homework, test, study the topic of discussion and other learning activities, teaching materials can also view the application, view the record of learning, learning communities into the share exchange, to break the barriers of time and space, using the Internet to expand Traditional teaching mode, better knowledge learning, improve personal accomplishment and self-learning ability.

Course teachers also bear the college English reading and writing, English writing and English grammar courses, with rich grammar teaching experience. Online course is divided into five units, the system is designed to sort out English grammar, and through discussion, and self-test tasks motivate students to independently explore the phenomenon of language, the use of grammar rules, and ultimately internalized grammatical competence. The course is introduced from grammatical competence self-test, explaining the words, phrases, syntax and time, body, state and style in chapters. The explanations of each grammar point are complemented by small tests, which are convenient for students to use while learning and enhance the practicality of grammar teaching. In order to enrich the form of courses, teachers and teaching assistants speaker design team produced more than 20 courses courseware, written more than 500 small road test questions, developed by the project team recorded 20 total duration of more than 160 minutes of video. Classes are open to all students and during the semester a total of about 3,500 students enroll in classes and join the program. In this MOOC-based college English grammar teaching, the author will study and discuss from the aspects of teaching activities, learner feedback and teaching experience.

\section{TEACHING ACTIVITIES}

Based on MOOC platform for college English grammar, teaching methods are described in as follows:

First, teacher making micro-teaching video and courseware is the first step in MOOC classroom. This step is the input stage of explicit grammar knowledge, which aims to help students establish a system of explicit grammar knowledge by means of fragmented systematic teaching. Grammar Online releases two teaching videos weekly on the platform. Each video only talks about one grammar point, and the duration is controlled within 10 minutes, so as to enable the students to complete a knowledge point learning within a focused time, Reduce student memory burden, improve learning efficiency. After the video attached to the targeted test and mark the grammar points of the movie fragment to enjoy outside the explicit output tasks and multimodal enhanced input to consolidate what you learned. According to the results of grammar self-test, students choose their own level of learning tasks, by watching the teaching video, learning multi-modal teaching self-study and complete the quiz. Students learn time, place, schedule and attendance can choose, fully meet the individual learning needs.

Second, discussion platform is another important part of MOOC classroom, but also to build an inquiry, collaborative learning atmosphere is an important way. Grammar Online has 256 students posting in forums for a total of 398 postings during the 15 week start of the course. Topics mainly involve the exchange of learning experience, the understanding of learning content, the study of learning confusion, the learning experience and curriculum construction advice and suggestions. Students, teachers and teachers in the forum not only completed the traditional aspects of the discussion session, but also tried a new grammar learning model: In an open online learning environment, mainly by students through cooperative learning, learning to explore Grasp the grammar knowledge, supplemented by teachers to guide and Q \& A.

Third, at the end of each unit, we have all designed exercises such as dictation, pictorial representation, essay rewriting, scene conversations or team lectures based on the grammatical structure of the unit, requiring students to complete their work in teams and submit videos, documents, etc.. The MOOC platform supports both student peer reviews, teachers and TA teams provide student evaluation indicators and guidelines, and students rate or critiqued other team assignments based on evaluation criteria. Xiaohong Du $(2010,11)$ argues that it is an effective means to help students to improve their grammatical control ability by guiding the group to evaluate and apply the grammatical knowledge to solve practical problems in the multimedia platform.

\section{LEARNERS' FEEDBACKS}

At the end of the semester's course, we distributed a questionnaire to a total of 3,993 learners registered with "Grammar Online" through the Superstar Learning Platform. The survey included the learner's learning experience, learning outcomes, preference for online learning and traditional classes as well as the views and suggestions on the curriculum and other four aspects. A total of 2374 valid questionnaires were collected, accounting for $68 \%$ of the learners, with statistical significance and research value.

\section{A. Learning Experience}

In order to understand the learners' acceptance of the various learning sessions in online classrooms, we have designed five options such as "very like", "like", "normal", "do not like" and "do not like" and then remember 5,4,3,2,1 points. Leave a subjective question after each study item, and ask the learner to write out the subordinate points, that is, the opinions and suggestions on the learning link. It can be seen that the video teaching is most popular among students. The main basis for grading is "intuitive and vivid", "you can learn some complex grammatical knowledge repeatedly" and "the teacher has a sense of closeness". Teaching of multimodal courseware has also been recognized by most students. However, many learners still report that the information 
content of multimodal resources is too large, which leads to the process of extracurricular autonomous learning is too tight and students are not comfortable with it. The students who use grammatical knowledge to solve practical problems have a higher score in their homework assignments. Although students often find it difficult to reflect tasks during the course, students can challenge themselves in a real language learning environment by means of teamwork and information access. Build and acquire grammar knowledge, form grammar ability, thus further stimulate the interest in learning. The reasons for the low acceptance of the interactive discussion are mainly that students and teachers are less involved in discussions and that students' questions cannot be answered in time or even without feedback. Eventually, the discussion area becomes a place where students can vomit. Another reason is that discussion forums have no alternative advantages over existing instant messaging tools such as the QQ group. Teachers and students have become accustomed to using teaching groups. Sometimes the discussion forum in online classrooms seems dispensable.

\section{B. Learning Effect}

The learning effect of students is the teaching result of language course. We learned "new grammar knowledge", "deepened understanding of existing grammar knowledge", "ability to incorporate grammatical knowledge into practical language use", "increased interest in grammar learning", "improved the interest in using MOOC courses to learn" and other aspects of the test, the students to five levels such as "strongly agree", "agree", "general", "not agree", "strongly disagree" in accordance with 5, 4, 3, 2, 1 score in turn. We are gratified to see that students have given this course a very high degree of recognition in terms of the training of knowledge, abilities and learning methods.

\section{The Preference for Online Learning and Traditional Classes}

When asked if they prefer online or traditional classes to learn English grammar, 52\% of students chose online classes for the following reasons: time to learn, pace of progress and speed on their own; video, courseware rich and difficult Understand the knowledge points can be repeated learning repeated viewing, learning anxiety less; computers, tablets, mobile phones can $\log$ in to the classroom, easy to learn online anytime, anywhere; learning content can be adjusted and selected according to their own circumstances and needs; group task interesting, diverse forms . Another $25 \%$ of the students chose the traditional classroom for the following reasons: The traditional classroom can communicate face-toface with teachers and classmates to better understand and interact with each other. They can get teachers' guidance and answering questions more promptly. Sex; online classes are more difficult to focus on, susceptible to outside interference and temptation; poor foundation, it is difficult to complete multi-modal online class. $23 \%$ of students think there are pros and cons in online classrooms and traditional classrooms, and their influence on their study is not much different.

\section{Comments and Suggestions on the Course}

As students' foundations vary greatly, they also have totally different views on the difficulty of the course. Some students think it is too hard to learn grammar in English and only want to cover the grammar points involved in Level 4-6. Students hope to learn finer grammar knowledge and add more practical exercises on grammar in listening, speaking, reading and writing. The suggestions given by students include: enriching learning resources, providing more multimodal language materials; strengthening language application, designing more listening, reading, writing and translating exercises; increasing the amount of quizzes and enrichment of quizzes; Video and audio quality; teachers and teaching assistants participate more in discussion forums and Q \& A interaction; increase relevant knowledge point links to enhance user friendliness and make it easier for students to find what they want to learn more quickly.

\section{Pedagogical ReFlection}

From the beginning of construction of the "grammar online" course to the end of the semester, we conducted a total of three interviews with the lecturers and teaching assistant teams. The feedback was mainly concentrated on the workload and teaching methods.

\section{A. Online Construction Workload}

Each MOOC course requires a 6-10 minute micro video recording in advance. In order to achieve better image quality and sound quality, most micro-video needs to be repeatedly recorded and processed using professional software and tools. Teachers need to spend more time and energy to prepare and teach. Due to the fragmentation of the course content, the related courseware, quizzes, and group tasks require specialized development and design. During the course, the $\mathrm{Q} \& \mathrm{~A}$ of the discussion area, the manual correction of the subjective questions during the quizzes, the supervision and guidance of the group tasks, which occupied a lot of time and energy of the students of the teaching assistant team, and some rare and complex syntax phenomena exceeded Their range of knowledge cannot give the correct answer.

\section{B. New Teaching Methods Challenge}

Lecturers reported that due to the lack of a lively atmosphere in traditional classrooms and the inability to receive the students' eyes and language feedback, the recording of MOOC micro-video lectures can only be based on past teaching experience and imagination of the state of learners, with a sense of self-talk. It is often difficult to accept unnatural sounds and emotions when looking back after recording a video, resulting in several rework. In addition, the micro-video will be cut into pieces of teaching content, and many grammar phenomenon does not appear independently, teachers must carefully design knowledge points to ensure that fragmented learning knowledge system. 


\section{CONCLUSION}

MOOC is a new network teaching mode, whose validity can only be improved after careful design and consideration. Considering that developing and constructing MOOC courses is costly and time-consuming, the development of MOOC courses should be considered in cooperation with publishers, platform developers and other colleges and universities to continuously launch high-quality online courses.

\section{REFERENCES}

[1] Jack C. Richards, Randi Reppen, "Towards a Pedagogy of Grammar Instruction”, RELC Journal 45(1), 2014.

[2] John Flowedew, Matthew Peacock, Research Perspectives on English for Academic Purposes, Cambridge University Press, Cambridge, 2014.

[3] Manli Li, "Exploring the Institutional Design Principles of Moocs" Tsinghua Journal of Education, vol. 34(4), pp. 13-21, 2013.

[4] Qiaochun Bi, "Five Major Domestic MOOC Platforms to Learners", China Education Network, vol. 10, pp 61-64, 2015.

[5] Xiaohong Du, "A Study on the Construction of Implicit Grammatical Ability on the Basis of Inquiry Learning" Journal of Tianjin Foreign Studies University, vol. 11, pp. 62-66, 2010. 